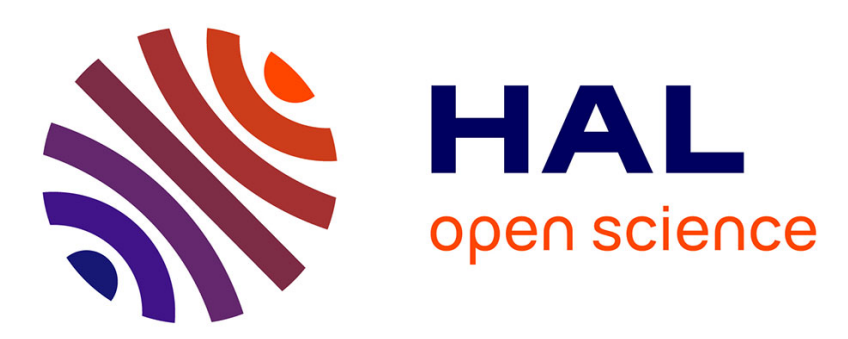

\title{
Combining Cyanometalates and Coordination Clusters: An Alternative Synthetic Route toward Original Molecular Materials
}

Abhishake Mondal, Pierre-Igor Dassié, Lise-Marie Chamoreau, Yves Journaux, Miguel Julve, Laurent Lisnard, Rodrigue Lescouëzec

\section{To cite this version:}

Abhishake Mondal, Pierre-Igor Dassié, Lise-Marie Chamoreau, Yves Journaux, Miguel Julve, et al.. Combining Cyanometalates and Coordination Clusters: An Alternative Synthetic Route toward Original Molecular Materials. Crystal Growth \& Design, 2013, 13 (10), pp.4190-4194. 10.1021/cg401117u . hal-02326580

\section{HAL Id: hal-02326580 \\ https://hal.science/hal-02326580}

Submitted on 30 Oct 2019

HAL is a multi-disciplinary open access archive for the deposit and dissemination of scientific research documents, whether they are published or not. The documents may come from teaching and research institutions in France or abroad, or from public or private research centers.
L'archive ouverte pluridisciplinaire HAL, est destinée au dépôt et à la diffusion de documents scientifiques de niveau recherche, publiés ou non, émanant des établissements d'enseignement et de recherche français ou étrangers, des laboratoires publics ou privés. 


\title{
Combining cyanometalates and coordination
}

\section{clusters: an alternative synthetic route toward}

\section{original molecular materials.}

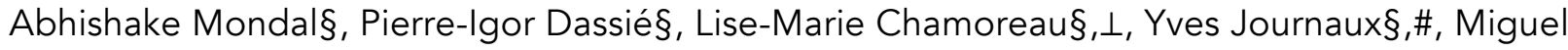
Julve,‡ Laurent Lisnard*§,\#, Rodrigue Lescouëzec*§.

§. Institut Parisien de Chimie Moléculaire, UMR 7201, UPMC Univ. Paris 06, Paris, 75005, France. \#. CNRS, Institut Parisien de Chimie Moléculaire, UMR 7201, Paris, 75005, France.

. Centre de résolution structurale, Institut Parisien de Chimie Moléculaire, Paris, 75005, France.

‡ Instituto de Ciencia Molecular (ICMol), Facultat de Química, Universitat de València, C/ Catedrático José Beltrán 2, 46980 Paterna, València, Spain.
\end{abstract}

With the discovery of molecules or molecule-based compounds that can display blocked magnetization, magnetic ordering or switchable magnetic bistability, the research efforts devoted to molecular magnetic materials have considerably increased over the past two decades, fully exploiting the advantages of the bottom-up approach. ${ }^{1-4}$ This research field focuses on promising properties for potential technological applications such as information storage, quantum computing and spintronics at the molecular scale, but it also provides fundamental insights into original quantum phenomena. ${ }^{5,6}$ Coordination chemists have developed efficient synthetic tools for the preparation of interesting magnetic systems. Overall 
two strategies are mainly used: the programmed assembly and the serendipitous selfassembly. ${ }^{7}$ The former consists in the preparation of specific building blocks that possess desired topology and electronic information and their use to form predictable architectures with targeted magnetic properties. The latter lies on the use of sensibly chosen ligands that display multi-binding modes and can thus promote magnetic exchange between several metal ions, with no assumptions or control on the shapes and the nuclearities of the final products. The programmed assembly approach is well illustrated with the use of metalloligands containing oxalate, oxamate or Schiff-base ligands. ${ }^{8-10}$ Cyanometalates also constitute excellent examples of tunable building blocks and they have successfully led to a broad variety of molecule-based magnets. ${ }^{11,12}$ In particular, partially blocked cyanometalates have afforded single-chain magnets (SCMs) and they are especially relevant for the preparation of photomagnetic molecules. ${ }^{13,14}$ Regarding the serendipitous self-assembly strategy, its efficiency is plainly demonstrated for the preparation of single-molecule magnets (SMMs) since serendipitously formed coordination clusters have provided to date the best examples of SMMs. ${ }^{15,16}$ They furthermore represent a formidable class of polymetallic molecular compounds with an impressive variety of shapes, sizes or compositions and they can in turn be considered as attractive starting materials. Beside these two well-known synthetic approaches, the magneto-chemists are actively exploring new routes aiming at the synthesis of sophisticated magnetic materials. For instance, the relatively recent use of polymetallic SMMs as building units and their further assembling through organic linkers has been established as original strategy. ${ }^{17,18}$ So is the use of paramagnetic cyanometalates to connect compartmental-ligandbased heterometallic complexes. ${ }^{19-23}$ The latter approach has indeed been established as a reliable route to reach heterotrimetallic paramagnetic complexes. ${ }^{23}$ Nonetheless, the former strategy focuses primarily on SMMs as building blocks and it remains not yet fully investigated with paramagnetic linkers and the latter one lies so far on polymetallic building blocks that could seem - when compared to oxo/carboxylato coordination clusters - limited in terms of nuclearity or lacking flexibility. Alternatively we have undertaken the study of the reactivity of cyanide-bearing metalloligands towards carboxylato-based clusters, our first result consisting in a unique cubic nanocage which apexes are defined by $\mathrm{fac}-\left[\mathrm{Fe}(\mathrm{Tp})(\mathrm{CN})_{3}\right]$ units and $\left\{\mathrm{Co}_{3}\left(\mu_{3}-\right.\right.$ 
$\mathrm{OH})\left(\right.$ piv) $\left.{ }_{4}\right\}$ triangles $[\mathrm{Tp}=$ tris(pyrazolyl)borate, Hpiv = 2,2'-dimethylpropionic acid, commonly referred as pivalic acid)]. ${ }^{24}$ This appealing preliminary result led us to investigate the reactivity of the fac- $\left[\mathrm{Fe}(\mathrm{Tp})(\mathrm{CN})_{3}\right]^{-}$complex towards other trigonal hydroxo-bridged coordination clusters. We present here the preparation, crystal structure determination and preliminary magnetic study of the novel two-dimensional (2-D) compound of formula $\left[\left\{\mathrm{Fe}(\mathrm{Tp})(\mu-\mathrm{CN})_{3}\right\}_{2}\left\{\mathrm{Cu}_{3}\left(\mu_{3}-\mathrm{OH}\right)(\mu-\right.\right.$ pz) $\left.\left.)_{3}\left(\mu-\mathrm{OOCCH}_{3}\right)\left(\mathrm{H}_{2} \mathrm{O}\right)_{0.5}\right\}_{2}\right] \cdot \mathrm{EtOH}(\mathbf{1})(\mathrm{pz}=$ pyrazolate), which results from the assembling of the mononuclear complex $\left[\mathrm{Fe}(\mathrm{Tp})(\mathrm{CN})_{3}\right]^{-}$and the hydroxo-centered tricopper(II) unit $\left[\mathrm{Cu}_{3}\left(\mu_{3}-\mathrm{OH}\right)(\mu-\right.$ $\left.\mathrm{pz})_{3}\right]^{2+}$ (see SI for experimental details).

1 crystallizes in the $P-1$ space group ${ }^{25}$ with a neutral heterobimetallic 2-D structure extending the ac plane (Fig. 1a). Each layer is constituted by zigzag ladder-like chains running parallel to the crystallographic a axis where regular alternating tris-monodentate $\left[\mathrm{Fe}(1)(\mathrm{Tp})(\mathrm{CN})_{3}\right]^{-}$units and the $\mathrm{Cu}(1) / \mathrm{Cu}(2)$ atoms from the $\left[\mathrm{Cu}_{3}\left(\left(\mu_{3}-\mathrm{OH}\right)(\mu-\mathrm{pz})_{3}\left(\mathrm{OOCH}_{3}\right)\right]^{+}\right.$triangles occurs along the rods, the rungs being defined by centrosymmetric $\mathrm{Fe}(1) \mathrm{Cu}(1) \mathrm{Fe}(1 \mathrm{a}) \mathrm{Cu}(1 \mathrm{a})$ square motifs [symmetry code: (a) $=-1-x, 2-y, 1-z ;]$ (Fig. 1b). These double chains are further interlinked along the crystallographic $c$ axis by double $\mu$-oxo(acetate) bridges involving the outer $\mathrm{Cu}(3)$ and $\mathrm{Cu}(3 \mathrm{c})$ atoms [symmetry code: (c) = 2-x, 2-y, 2-z] from tricopper(II) units of adjacent chains (Fig. 1c). The resulting layers exhibit a parallel stacking along the $b$ axis and they are well separated from each other, the shortest interlayer metal-metal distance being 8.7657(9) A (Fig. S1).

Each iron(III) ion is coordinated by three Tp nitrogen atoms and three cyanide carbon atoms with a $\mathrm{C}_{3 v}$ symmetry (Fig. 2). The values of the three $\mathrm{Fe}(1)-\mathrm{C}$ distances are in the very narrow 1.909(4)-1.922(4) A range and they are in agreement with those observed in previous magnetostructurally characterized low-spin iron(III) mononuclear species containing the fac-[Fe(Tp)(CN) $]_{3}^{-}$ anion $[1.910(6)-1.930(3) \AA] .{ }^{26,27}$ The cyanide stretching vibration $[v(C \equiv N)]$ in the infrared spectrum of $\mathbf{1}$ is located at $2162 \mathrm{~cm}^{-1}$ (see Supporting Information) and is consistent with the presence of bridging cyanide only (to be compared with peaks in the $2118-2129 \mathrm{~cm}^{-1}$ range for the terminal cyanide ligands in the mononuclear fac- $\left[\mathrm{Fe}(\mathrm{Tp})(\mathrm{CN})_{3}\right]^{-}$species). The $\mathrm{Fe}(1)-\mathrm{C} \equiv \mathrm{N}$ angles are close to linearity with values ranging from $172.6(3)$ to $175.8(4)^{\circ}$. However, a significant bending is observed on the edges of the $\mathrm{Fe}(1) \mathrm{Cu}(1) \mathrm{Fe}(1 \mathrm{a}) \mathrm{Cu}(1 \mathrm{a})$ square motifs $\left[\mathrm{Cu}(1)-\mathrm{N}(1)-\mathrm{C}(1)=164.9(3)^{\circ}\right.$ and $\left.\mathrm{Cu}(1)-\mathrm{N}(2)-\mathrm{C}(2)=150.7(4)^{\circ}\right]$ (Fig. 2) whereas the intersquare 
$\mathrm{Fe}(1)-\mathrm{C}-\mathrm{N}-\mathrm{Cu}(2 \mathrm{~b})$ bridge is closer to linearity $\left[\mathrm{Cu}(2 \mathrm{~b})-\mathrm{N}(3)-\mathrm{C}(3)=176.0(3)^{\circ}\right.$; symmetry code: (b) $=-1+x, y, z]$. The iron-copper distances across the cyanide bridges in 1 are 5.00543(8), 4.9834(6) and 5.1316(8) $\AA$ for $\mathrm{Fe}(1) \cdots \mathrm{Cu}(2 \mathrm{~b}), \mathrm{Fe}(1) \cdots \mathrm{Cu}(1)$ and $\mathrm{Fe}(1) \cdots \mathrm{Cu}(1 \mathrm{a})$ respectively and compare well with previously reported values in discrete rectangular ${ }^{28}$ and pentanuclear motifs $^{29}$ as well as in 1-D compounds that display a similar fragment. ${ }^{30-32}$

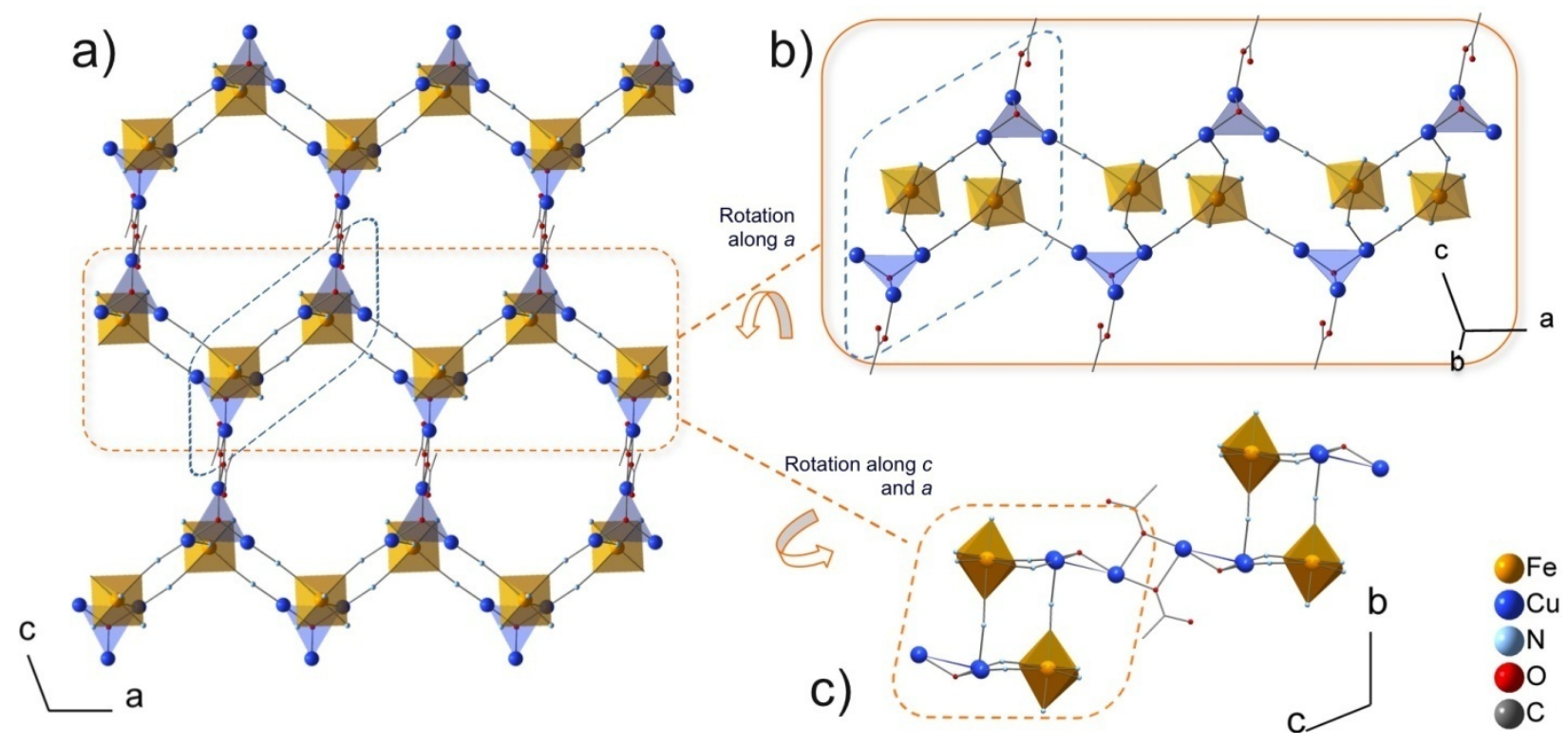

Figure 1. Schematic view of the 2-D structuring of $\mathbf{1}$ in the crystal. Tp and pz ligands and solvent molecules as well as $\mathrm{H}$ atoms have been omitted for clarity.

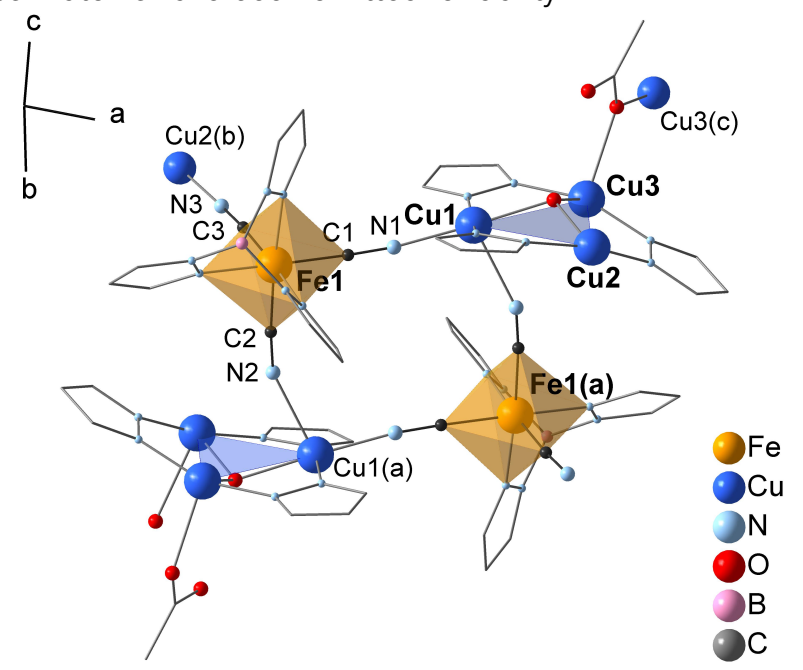

Figure 2. Representation of the $\left\{\mathrm{Fe}_{2}\left(\mathrm{Cu}_{3}\right)_{2}\right\}$ square building-unit in 1. $\mathrm{H}$ atoms are omitted for clarity. [Symmetry codes: (a) $=-1-x, 2-y, 1-z ;(b)=-1+x, y, z ;(c)=2-x, 2-y, 2-z]$. 
As in the parent compound of formula $\left[\mathrm{Cu}_{3}(\mu-\mathrm{OH})(\mu-\mathrm{pz})_{3}(\mathrm{Hpz})\left(\mathrm{NO}_{3}\right)_{2}\right]_{1}^{33}$ the tricopper(II) unit in 1 can be described as a triangle with the $\mathrm{Cu}(1), \mathrm{Cu}(2)$ and $\mathrm{Cu}(3)$ atoms at the apexes, single pyrazolate ligands along the edges and a $\mu_{3}$-hydroxo group capping the triangle (the oxygen atom is located at $0.6 \AA$ from the triangle plane). Within the triangle the copper-copper distances are in the 3.2262(7)-3.3847(7) $\AA$ range [av. $3.30 \AA]$. In the pyramidal $\left\{\mathrm{Cu}_{3}(\mu-\mathrm{OH})\right\}$ core, the three $\mathrm{Cu}-\mathrm{O}(1)$ bond distances range from 1.986(2) to 2.026(2) and the values of the $\mathrm{Cu}$ $\mathrm{O}(1)-\mathrm{Cu}^{\prime}$ angles are found between $106.84(12)$ and $116.65(12)^{\circ}$. In the peripheral $\{\mathrm{Cu}(\mathrm{N}-\mathrm{N})\}_{3}$ ring, the $\mathrm{Cu}-\mathrm{N}$ distances are homogeneous, from 1.942(3) to 1.952(3) $\AA$. $\mathrm{Cu}(1)$ and $\mathrm{Cu}(3)$ are five-coordinate with two pyrazolate-nitrogen, the hydroxo-oxygen and either two cyanidenitrogen $[\mathrm{Cu}(1)]$ or two carboxylate-oxygen atoms $[\mathrm{Cu}(3)]$ building distorted square pyramidal surroundings. $\mathrm{Cu}(2)$ is alternatively in square pyramidal $[\mathrm{Cu}(2) \mathrm{N}(15) \mathrm{N}(10) \mathrm{O}(1) \mathrm{N}(3) \mathrm{O}(4)]$ or in square planar $[\mathrm{Cu}(1) \mathrm{N}(15) \mathrm{N}(10) \mathrm{O}(1) \mathrm{N}(3)]$ environments depending on the presence or absence of a coordinated water molecule $[\mathrm{O}(4)]$. The $[\mathrm{Cu}(3) \mathrm{O}(2) \mathrm{O}(2 \mathrm{c}) \mathrm{Cu}(3 \mathrm{c}]$ fragment that results from the double $\mu$-acetato bridge linking the chains has copper atoms coordinated to oxygen atoms in equatorial and in axial positions, the $\mathrm{Cu}-\mathrm{O}$ bond lengths being respectively 1.981(3) and 2.348(3) $\AA$ and the bridgehead angle [Cu(3)-O(2)-Cu(3c)] being 102.4(1) ${ }^{\circ}$. Hydrogen bonds involving the coordinated water molecule, the hydroxo group and the acetate uncoordinated oxygen atom $(O(1) \cdots O(3): 2.791(5) \AA ; O(3) \cdots O(4): 2.62(1) \AA)$ contribute to the stabilization of the layered structure (Fig. S2).

In our previous work, ${ }^{24}$ the fac- $\left[\mathrm{Fe}(\mathrm{Tp})(\mathrm{CN})_{3}\right]^{-}$unit acted as a tris-monodentate ligand toward three cobalt(II) ions from three different $\left\{\mathrm{CO}_{3}\right\}$ triangles. In each triangle the cobalt atoms were thus coordinated to three different iron atoms through orthogonal cyanide ligands, leading to a discrete cubic motif. The rigidity of the metalloligand undoubtedly played an important role in the formation of this geometry. In the present study, we have used a trigonal $\left\{\mathrm{Cu}_{3}\right\}$ building block exhibiting a shape similar to that of the $\left\{\mathrm{CO}_{3}\right\}$ triangles. As in the case of the cobalt triangles, the fac-[Fe(Tp)(CN) $]^{-}$unit adopts a tris-monodentate coordination mode toward three copper(II) ions from three $\left\{\mathrm{Cu}_{3}\right\}$ triangles. Although the orthogonal arrangement of the cyanide ligands favors the $\left\{\mathrm{Fe}_{2}-\mathrm{Cu}_{2}\right\}$ square motifs, the presence of a competitive bridging ligand -the 
acetate ion- is responsible for the formation of the unprecedented bidimensional architecture in 1.

Variable-temperature dc magnetic susceptibility measurements have been performed on a crushed polycrystalline sample of 1 under applied magnetic fields of $2.5 \mathrm{kOe}(2-300 \mathrm{~K})$ and $250 \mathrm{Oe}(2-30 \mathrm{~K})$. The $\chi_{M} T$ vs. $T$ plot (where $\chi_{M}$ is the molar magnetic susceptibility per $\left\{\mathrm{Fe}_{2} \mathrm{Cu}_{6}\right\}$ unit) is shown in Fig. 3. The $\chi_{M} T$ value at room temperature is $2.19 \mathrm{~cm}^{3} \mathrm{~mol}^{-1} \mathrm{~K}$, a value that is well below the calculated one for a set of two low-spin iron(III) and six copper(II) ions magnetically non-interacting $\left(\chi_{M} T=3.75 \mathrm{~cm}^{3} \mathrm{~mol}^{-1} \mathrm{~K}\right.$ with $\mathrm{S}_{\mathrm{Fe}}=\mathrm{S}_{\mathrm{Cu}}=1 / 2, g_{\mathrm{Fe}}=2.6,{ }^{34}$ and $g_{\mathrm{Cu}}=$ 2.1). Upon cooling, $\chi_{M} T$ smoothly decreases to attain a quasi plateau between 80 and $40 \mathrm{~K}$ (with $\chi_{M} T \sim 1.7 \mathrm{~cm}^{3} \mathrm{~K} \mathrm{~mol}^{-1}$ ) and it further sharply increases to $4.33 \mathrm{~cm}^{3} \mathrm{~mol}^{-1} \mathrm{~K}$ at $2.0 \mathrm{~K}$. The interpretation and analysis of these magnetic data are made difficult by the complex topology of 1 and the coexistence of various exchange pathways: (i) the cyanide bridges between the low-spin iron(III) and the copper(II) ions within the ladder-like motif; (ii) the hydroxo and pyrazolate bridges in the tricopper(II) units; (iii) and the double oxo(acetate) connection between copper(II) ions from adjacent ladder-like chains.

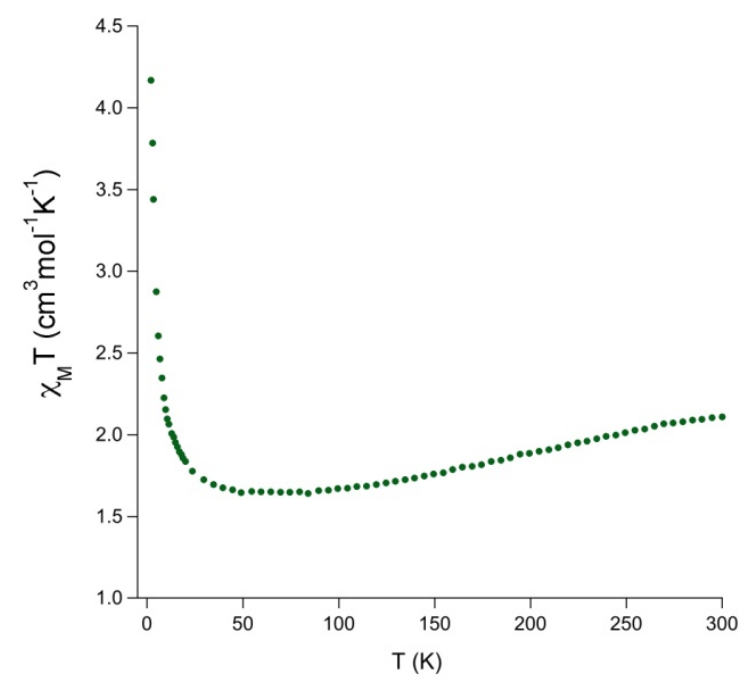

Figure 3. $\chi_{M} T$ vs. $T$ plot for 1, measured at $2.5 \mathrm{kOe}$ between 300 and $2 \mathrm{~K}$.

There is no model to treat the magnetic data of $\mathbf{1}$ but a qualitative description of its magnetic behavior can be made in the light of the results found in the literature concerning the 
three exchange pathways involved here. First of all, the small $\chi_{M} T$ value observed at room temperature points out the occurrence of significant antiferromagnetic exchange interactions. Indeed, the pyrazolate hydroxo-centered $\left\{\mathrm{Cu}_{3}\right\}$ clusters are known to exhibit both strong antiferromagnetic interaction $\left(150<|J|<210 \mathrm{~cm}^{-1}\right)$ and significant antisymmetric exchange interaction, resulting in $1 / 2$ ground spin states. ${ }^{35}$ In contrast the other two exchange pathways exhibit weak exchange interactions. The orbital contribution of the low-spin iron(III) centers and the relatively strong antiferromagnetic interaction in the tricopper(II) triangles should thus be responsible for the observed decrease of $\chi_{M} T$ in the high temperature region. A smaller ferromagnetic coupling between the low-spin iron(III) and the resulting spin doublet from the tricopper(II) unit would account for the increase of the $\chi_{\mathrm{M}} T$ value in the low temperature domain. Indeed, ferromagnetic interactions varying from +17 to $+34.4 \mathrm{~cm}^{-1}$ have been reported for magneto-structurally characterized examples of $\{$ Felll(Tp)(CN)2(m-CN)Cull\} motifs. ${ }^{28-32}$ The possible magnetic coupling through the double oxo(acetate) bridge is necessarily weak. It corresponds to an equatorial-axial exchange pathway and the literature data reveal that its ability to mediate magnetic interactions is very low ( $\mathrm{J}$ values from -2.36 to $+1.95 \mathrm{~cm}-1) .{ }^{36}$ The shape of the $\mathrm{M}$ vs. $\mathrm{H}$ plot at $2.0 \mathrm{~K}$ (Fig. S3) supports the occurrence of a ferromagnetic interaction between the low-spin iron(III) and the doublet spin state of the tricopper(II) unit within the ladder-like motif. In addition, the absence of inflexion point in such a curve at very low applied fields is consistent with a extremely weak interchain antiferromagnetic interaction (if any) through the (iii) pathway or well a very weak ferromagnetic coupling across it. Most likely, the magnetic behavior observed for 1 obeys to the (i) and (ii) pathways.

The $\left\{\mathrm{Cu}_{3}\left(\mu_{3}-\mathrm{OH}\right)(\mu-\mathrm{pz})_{3}\right\}$ cluster has been successfully used to generate supramolecular assemblies and multidimensional networks when associated to organic linkers or coordinating counter-anions such as acetate, ${ }^{33,37-43}$ Here we extend its use with the first example of its assembling with a metalloligand. Similarly, the $\mathrm{fac}-\left[\mathrm{Fe}(\mathrm{Tp})(\mathrm{CN})_{3}\right]^{-}$complex used as a metalloligand is known to yield molecular or one-dimensional assemblies with paramagnetic ions, ${ }^{44} 1$ being the first example of $\left\{\mathrm{Fe}(\mathrm{Tp})(\mathrm{CN})_{3}\right\}$-based 2-D network. Of course, the nature of the trimetallic node and the role of the acetate ligand are far from innocent in this assembly. 
More generally the originality of $\mathbf{1}$ highlights the benefits one can gain associating cyanometalates with coordination clusters. Indeed the impressive amount of accessible coordination clusters provides a fascinating set of building blocks with many tuneable parameters (nuclearity, charge, geometry, flexibility, co-ligand, etc.). Their association with the comparably rich family of tuneable building blocks that are the cyanometalates constitutes therefore a formidable study where uncommon architectures should undoubtedly be encountered and where the relationship between the starting materials' intrinsic features and the assembled entities' properties, once explored, should lead to interesting magnetic properties.

\section{ASSOCIATED CONTENT}

Supporting Information. X-ray crystallographic files for $\mathbf{1}$ in cif format; Experimental details for the preparation and the characterization of 1; Figure detailing crystal packing (S1); the hydrogen bonds (S2); plots of $M$ vs. $H(\mathrm{~S} 3), \chi_{M}$ vs. $T$ and $1 / \chi_{M}$ vs. $T$ (S4) for 1 . This material is available free of charge via the Internet at http://pubs.acs.org.

\section{AUTHOR INFORMATION}

\section{Corresponding Authors}

rodrigue.lescouezec@upmc.fr, laurent.lisnard@upmc.fr

Phone: +331442730 75; Fax: +33144273841.

\section{ACKNOWLEDGMENT}

This work was supported by the Ministère de I'Enseignement Supérieur et de la Recherche (MESR, France), the Centre National de la Recherche Scientifique (CNRS), the Erasmus Mundus program (lot 13), the Agence Nationale de la Recherche (Project: ANR-08-BLAN-0186-01) and the Ministerio Español de Ciencia e Innovación (Project CTQ 2010-15364) and Generalitat Valenciana (PROMETEO/2009/108 and ISIC2012/002). We acknowledge SOLEIL for provision of synchrotron radiation facilities and we would like to thank Pierre Fertey for his help and support in using the CRISTAL beamline (Proposal 20120026). 


\section{REFERENCES}

(1) Miller, J. S.; Drillon, M.; Editors. Book series, "Magnetism: Molecules to Materials" I-V; Wiley-VCH, Weinheim, 2005.

(2) Special issue on Molecular Magnets Dalton Trans. 2010, 39, 4653-5040.

(3) Special issue on Molecular Magnets Chem. Soc. Rev. 2011, 40, 3053-3368.

(4) Special issue: Frontier and Perspectives in Molecule-Based Quantum Magnet Dalton Trans. 2012, 41, 13543-13766.

(5) Gatteschi, D.; Sessoli, R.; Villain, J. Molecular Nanomagnets; Mesoscopic Physics and Nanotechnology; OUP Oxford, 2006.

(6) Winpenny, R. E. P.; Mclnnes, E. J. L. In Molecular Materials; John Wiley \& Sons, Ltd, 2010; pp. 281-348.

(7) Winpenny, R. E. P. J. Chem. Soc., Dalton Trans. 2002, 1-10.

(8) Dul, M.-C.; Pardo, E.; Lescouëzec, R.; Journaux, Y.; Ferrando-Soria, J.; Ruiz-Garcia, R.; Cano, J.; Julve, M.; Lloret, F.; Cangussu, D.; Pereira, C. L. M.; Stumpf, H. O.; Pasan, J.; Ruiz-Perez, C. Coord. Chem. Rev. 2010, 254, $2281-2296$.

(9) Marinescu, G.; Andruh, M.; Lloret, F.; Julve, M. Coord. Chem. Rev. 2011, 255, 161-185.

(10) Andruh, M.; Costes, J.-P.; Diaz, C.; Gao, S. Inorg. Chem. 2009, 48, 3342-3359.

(11) Shatruk, M.; Avendano, C.; Dunbar, K. R. Prog. Inorg. Chem. 2009, 56, 155-334.

(12) Rebilly, J.-N.; Mallah, T. Struct. Bonding (Berlin, Ger.) 2006, 122, 103-131.

(13) Lescouëzec, R.; Toma, L. M.; Vaissermann, J.; Verdaguer, M.; Delgado, F. S.; Ruiz-Perez, C.; Lloret, F.; Julve, M. Coord. Chem. Rev. 2005, 249, 2691-2729.

(14) Newton, G. N.; Nihei, M.; Oshio, H. Eur. J. Inorg. Chem. 2011, 2011, 3031-3042.

(15) Milios, C. J.; Vinslava, A.; Wernsdorfer, W.; Moggach, S.; Parsons, S.; Perlepes, S. P.; Christou, G.; Brechin, E. K. J. Am. Chem. Soc. 2007, 129, 2754-2755.

(16) Blagg, R. J.; Muryn, C. A.; Mclnnes, E. J. L.; Tuna, F.; Winpenny, R. E. P. Angew Chem Int Ed Engl 2011, 50, 6530-3.

(17) Miyasaka, H.; Yamashita, M. Dalton Transactions 2007, 399.

(18) Roubeau, O.; Clerac, R. Eur. J. Inorg. Chem. 2008, 4325-4342.

(19) Andruh, M. Chem. Commun. 2011, 47, 3025-3042.

(20) Jeon, I.-R.; Clérac, R. Dalton Transactions 2012, 41, 9569.

(21) Long, J.; Chamoreau, L.-M.; Mathonière, C.; Marvaud, V. Inorg. Chem. 2009, 48, 22-24.

(22) Alexandru, M.-G.; Visinescu, D.; Madalan, A. M.; Lloret, F.; Julve, M.; Andruh, M. Inorg. Chem. 2012, 51, 4906-4908.

(23) Palacios, M. A.; Mota, A. J.; Ruiz, J.; Hänninen, M. M.; Sillanpää, R.; Colacio, E. Inorg. Chem. 2012, 51, 7010-7012. 
(24) Mondal, A.; Durdevic, S.; Chamoreau, L.-M.; Journaux, Y.; Julve, M.; Lisnard, L.; Lescouëzec, R. Chem. Commun. 2013, 49, 1181-1183.

(25) XRD measurements have been performed in the Soleil synchrotron in Gif-sur-Yvette, France, on the CRISTAL beamline, see supporting information for details.

(26) Lescouëzec, R.; Vaissermann, J.; Lloret, F.; Julve, M.; Verdaguer, M. Inorg. Chem. 2002, 41, 5943-5945.

(27) Kim, J.; Han, S.; Cho, I.-K.; Choi, K. Y.; Heu, M.; Yoon, S.; Suh, B. J. Polyhedron 2004, 23, $1333-1339$.

(28) Liu, W.; Wang, C.-F.; Li, Y.-Z.; Zuo, J.-L.; You, X.-Z. Inorg. Chem. 2006, 45, 10058-10065.

(29) Wang, C.-F.; Zuo, J.-L.; Bartlett, B. M.; Song, Y.; Long, J. R.; You, X.-Z. J. Am. Chem. Soc. 2006, 128, 71627163.

(30) Wang, S.; Zuo, J.-L.; Gao, S.; Song, Y.; Zhou, H.-C.; Zhang, Y.-Z.; You, X.-Z. J. Am. Chem. Soc. 2004, 126, $8900-8901$.

(31) Wang, S.; Zuo, J.-L.; Zhou, H.-C.; Song, Y.; Gao, S.; You, X.-Z. Eur. J. Inorg. Chem. 2004, $2004,3681-3687$.

(32) Wen, H.-R.; Wang, C.-F.; Song, Y.; Gao, S.; Zuo, J.-L.; You, X.-Z. Inorg. Chem. 2006, 45, 8942-8949.

(33) Hulsbergen, F. B.; Ten, H.; Verschoor, G. C.; Reedijk, J.; Spek, A. L. J. Chem. Soc., Dalton Trans. 1983, $539-45$.

(34) Figgis, B. N.; Lewis, J.; Mabbs, F. E.; Webb, G. A. J. Chem. Soc. A 1967, 442-447.

(35) Ferrer, S.; Lloret, F.; Pardo, E.; Clemente-Juan, J. M.; Liu-González, M.; García-Granda, S. Inorg. Chem. 2012, 51, 985-1001.

(36) Simões, T. R. G.; Mambrini, R. V.; Reis, D. O.; Marinho, M. V.; Ribeiro, M. A.; Pinheiro, C. B.; FerrandoSoria, J.; Déniz, M.; Ruiz-Pérez, C.; Cangussu, D.; Stumpf, H. O.; Lloret, F.; Julve, M. Dalton Trans. 2013, 42, 57785795 , and references therein

(37) Casarin, M.; Corvaja, C.; Nicola, C. di; Falcomer, D.; Franco, L.; Monari, M.; Pandolfo, L.; Pettinari, C.; Piccinelli, F.; Tagliatesta, P. Inorg. Chem. 2004, 43, 5865-5876.

(38) Casarin, M.; Corvaja, C.; Di, N.; Falcomer, D.; Franco, L.; Monari, M.; Pandolfo, L.; Pettinari, C.; Piccinelli, F. Inorg. Chem. 2005, 44, 6265-6276.

(39) Casarin, M.; Cingolani, A.; Di, N.; Falcomer, D.; Monari, M.; Pandolfo, L.; Pettinari, C. Cryst. Growth Des. $2007,7,676-685$.

(40) Contaldi, S.; Di, N.; Garau, F.; Karabach, Y. Y.; Martins, L. M. D. R. S.; Monari, M.; Pandolfo, L.; Pettinari, C.; Pombeiro, A. J. L. Dalton Trans. 2009, 4928-4941.

(41) Di, N.; Garau, F.; Gazzano, M.; Monari, M.; Pandolfo, L.; Pettinari, C.; Pettinari, R. Cryst. Growth Des. 2010, $10,3120-3131$.

(42) Rivera-Carrillo, M.; Chakraborty, I.; Raptis, R. G. Cryst. Growth Des. 2010, 10, 2606-2612.

(43) Di, N.; Garau, F.; Gazzano, M.; Guedes, da S.; Lanza, A.; Monari, M.; Nestola, F.; Pandolfo, L.; Pettinari, C.; Pombeiro, A. J. L. Cryst. Growth Des. 2012, 12, 2890-2901.

(44) Wang, S.; Ding, X.-H.; Zuo, J.-L.; You, X.-Z.; Huang, W. Coord. Chem. Rev. 2011, 255, 1713-1732. 


\section{SYNOPSIS}

As an original synthetic route to molecular magnetic materials we have reacted partially blocked cyanometalates with preformed coordination cluster. The association of the fac$\left[\mathrm{Fe}(\mathrm{Tp})(\mathrm{CN})_{3}\right]^{-}$assembling metalloligand with the $\left[\mathrm{Cu}_{3}(\mathrm{OH})(\mathrm{pz})_{3}\right]^{2+}$ trigonal cluster has afforded a novel coordination network where the trimetallic copper nodes are linked by the iron complexes into chains and by coordinating acetate into a 2-D framework.

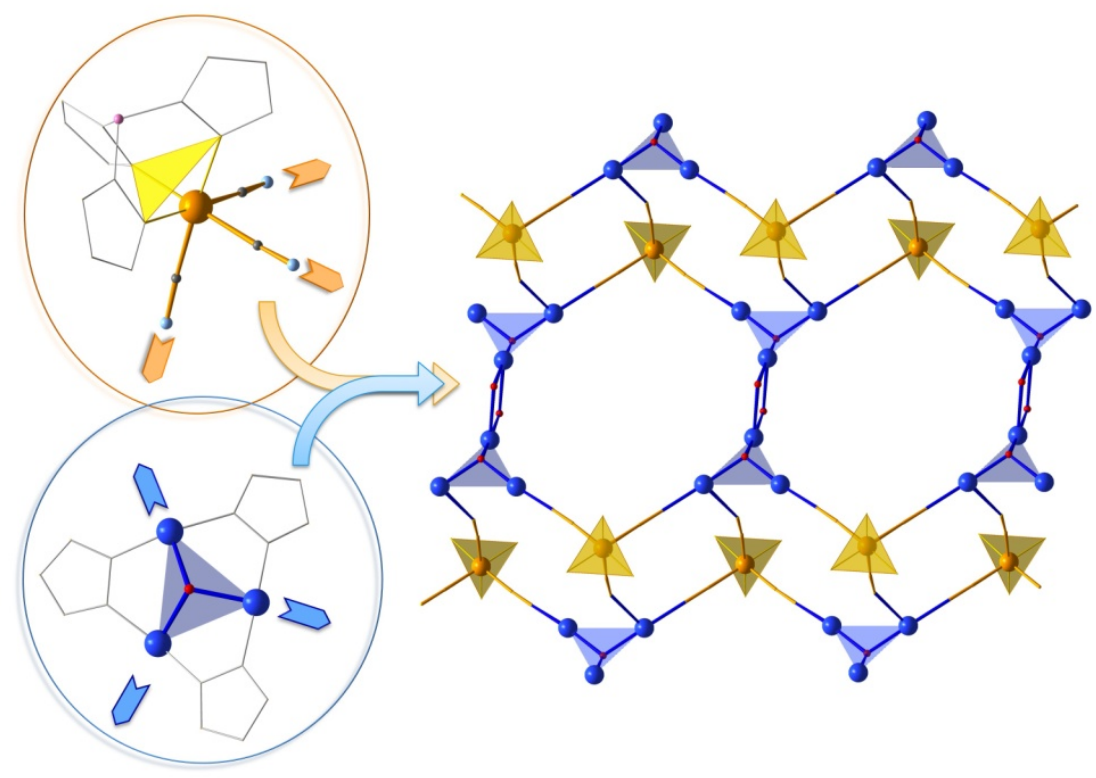




\section{Supplementary information.}

\section{Combining cyanometalates and coordination clusters: an alternative synthetic route to original molecular materials.}

Abhishake Mondal§, Pierre-lgor Dassié§, Lise-Marie Chamoreau§, $\perp$, Yves Journaux§,\#, Miguel Julveł Laurent Lisnard§,\#, Rodrigue Lescouëzec*§.

§. Institut Parisien de Chimie Moléculaire, UPMC Univ Paris 06, Paris, 75005, France.

\#. CNRS, Institut Parisien de Chimie Moléculaire, UMR 7201, Paris, 75005, France.

$\perp$. Centre de résolution structurale, Institut Parisien de Chimie Moléculaire, Paris, 75005, France.

‡ Instituto de Ciencia Molecular (ICMol), Facultat de Química, Universitat de València, C/ Catedrático José Beltrán 2, 46980 Paterna, València, Spain.

\section{Experimental section}

All reagents were used as purchased with no further purification.

$\left[\mathrm{PPh}_{4}\right]\left[\mathrm{Fe}(\mathrm{Tp})(\mathrm{CN})_{3}\right] \cdot \mathrm{H}_{2} \mathrm{O}$ (Tp=trispyrazolylborate), was prepared according to the literature procedure. ${ }^{1}\left[\mathrm{Cu}_{3}\left(\mu_{3}-\mathrm{OH}\right)(\mu-\mathrm{pz})\right]^{2+}$ was prepared in situ with slight modifications from the published procedure. ${ }^{2}$

\section{$\left[\left\{\mathrm{Fe}(\mathrm{Tp})(\mathrm{CN})_{3}\right\}_{2}\left\{\mathrm{Cu}_{3}(\mathrm{OH})(\mathrm{pz})_{3}\left(\mathrm{H}_{2} \mathrm{O}\right)_{0.5}\right\}_{2}(\mathrm{OAC})_{2}\right]$.EtOH (1).}

$\mathrm{Cu}(\mathrm{OAC})_{2} \cdot \mathrm{H}_{2} \mathrm{O}$ was dissolved in ethanol $(20 \mathrm{mg}, 0.1 \mathrm{mmol}, 8 \mathrm{~mL})$ followed by the addition of an equimolar ethanolic solution of pyrazol ( $\mathrm{Hpz}, 6.8 \mathrm{mg}, 0.1 \mathrm{mmol}, 8 \mathrm{~mL})$. The resulting deep blue solution was stirred for $10 \mathrm{~min}$ before the slow addition of $\left[\mathrm{PPh}_{4}\right]\left[\mathrm{Fe}(\mathrm{Tp})(\mathrm{CN})_{3}\right] \cdot \mathrm{H}_{2} \mathrm{O}(70.3 \mathrm{mg}, 0.1 \mathrm{mmol}, 1 \mathrm{eq})$ in ethanol $(8 \mathrm{~mL})$. The resulting orange solution was stirred for $1 \mathrm{hr}$, filtered and left to slowly evaporate standing at room temperature. After 8 days small orange plate-like crystals of 1 were collected by filtration and dried in air. Yield: $0.012 \mathrm{~g}$ (41 \%, based on Cu). IR (ATR, $\left.\mathrm{cm}^{-1}\right)$ : 3405(b); 3121(w); 2499(w); 2167(m); 1619(sh); 1560(m); 1500(m); 1405(s); 1380(s); 1312(s); 1280(w); 1211(s); 1179(m); 1116(s); 1045(s); 988(m); 966(sh); 921(w); 885(w); 821(w); 795(w); 752(s); 708(s); 655(m); 623(m); 526(w); 491(w); 404(w); 350(s); 221(m). Elemental analysis (\%) calculated 
for $\mathrm{C}_{48} \mathrm{H}_{54} \mathrm{~B}_{2} \mathrm{Cu}_{6} \mathrm{Fe}_{2} \mathrm{~N}_{30} \mathrm{O}_{8}\left(M_{\mathrm{r}}=1693.7 \mathrm{~g} \mathrm{~mol}^{-1}\right): \mathrm{C} 34.04, \mathrm{H}$ 3.21, $\mathrm{N}$ 24.81. Found: $\mathrm{C} 34.31, \mathrm{H}$ $3.41, \mathrm{~N} 25.21$.

Magnetic measurements in dc mode were performed on a Quantum Design MPMS SQUID on polycrystalline samples restrained in a plastic film. Data were corrected for the diamagnetism contributions of the samples using Pascal constants. The sample holder diamagnetism was measured and subtracted from the raw data.

ATR/FT-IR spectra were collected on a Bruker TENSOR 27 equipped with a simple reflexion ATR diamond plate of the Harrick MPV2 series.

\section{XRD, data collection and refinement.}

Crystal data for $1\left(\mathrm{C}_{24} \mathrm{H}_{27} \mathrm{BCu}_{3} \mathrm{FeN}_{15} \mathrm{O}_{4}\right)$ : orange plates, triclinic, space group $\mathrm{P}-1, a=$ $11.0142(3) \AA ⿻$, $b=13.8001(5) \AA, c=13.9728(4) \AA, \alpha=109.523(3)^{\circ}, \beta=108.236(3)^{\circ}, \gamma=$ $93.482(3)^{\circ} V=1868.48(11) \AA^{3}, Z=2, T=100(2) \mathrm{K}, \rho=1.505 \mathrm{~g} \cdot \mathrm{cm}^{-3}, F(000)=852, \mu=1.785$ $\mathrm{mm}^{-1}$.

The data collection for 1 was carried out at the CRISTAL beamline (SOLEIL, Paris) using the synchrotron radiation source $(\lambda=0.6683 \AA$ ) up to a maximum resolution of $0.72 \AA-1$, reaching $92 \%$ of completeness. The experiment temperature $(T=100 \mathrm{~K})$ was reached with a gas streamer (Cryolndustries of America), crystal-to-detector distance of $80 \mathrm{~mm}$. Wavelength was selected with a double crystal monochromator ( $\mathrm{Si} 111$ crystals) and sagittal (horizontal), focalization was achieved by bending the second crystal of the monochromator, the vertical focalization and harmonic rejections were made using mirrors. The beam attenuation was performed using Al (or $\mathrm{Cu}$ ) foils of different thicknesses inserted in the incident beam.

Data collection strategies were generated with the CrysAlisPro CCD package. Unit-cell parameters refinement and data reduction were carried out with CrysAlisPro RED. ${ }^{3}$

After absorption correction, the measured reflections were sorted, scaled and merged by using the SORTAV program. ${ }^{4,5}$ The structure was solved with ShelxS ${ }^{6}$ and refined with the SHELXL-97 program $^{6}$ (WinGX software package ${ }^{7}$ ).

Data refinement gives, using 454 parameters, $w R_{2}=0.1575$ (9518 unique reflections), $R_{1}=$ $0.0530(7858$ reflections with $I>20(I))$, GOF $=1.09$. 
CCDC-951875 contains the supplementary crystallographic data for this paper. These data can be obtained free of charge via www.ccdc.cam.ac.uk/conts/retrieving.html (or from the Cambridge Crystallographic Data Centre, 12 Union Road, Cambridge CB21EZ, UK; fax: (+44) 1223-336033; or deposit@ccdc.cam.uk).

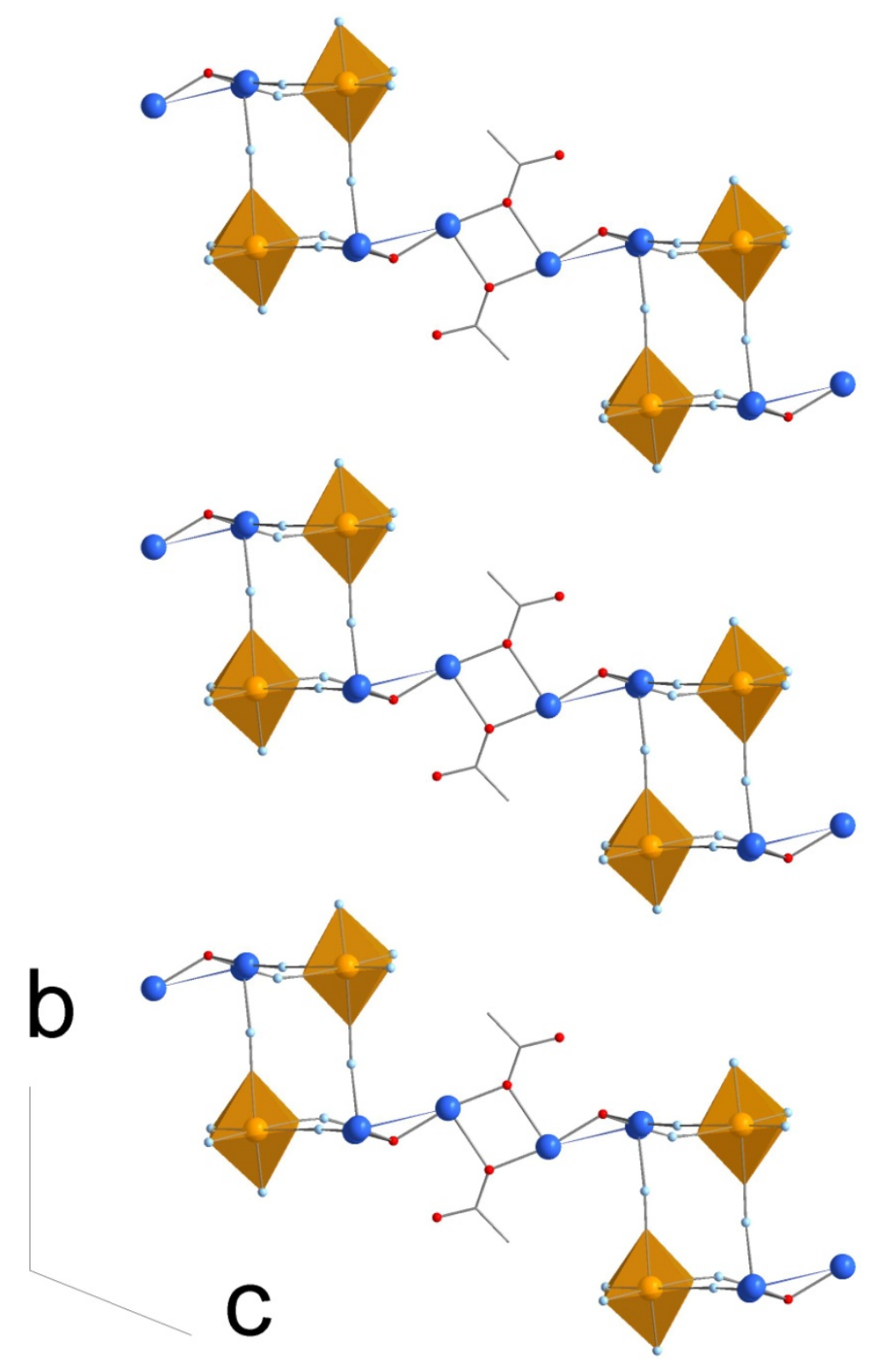

Figure S1: crystal packing of 1 along the $b$ axis. 


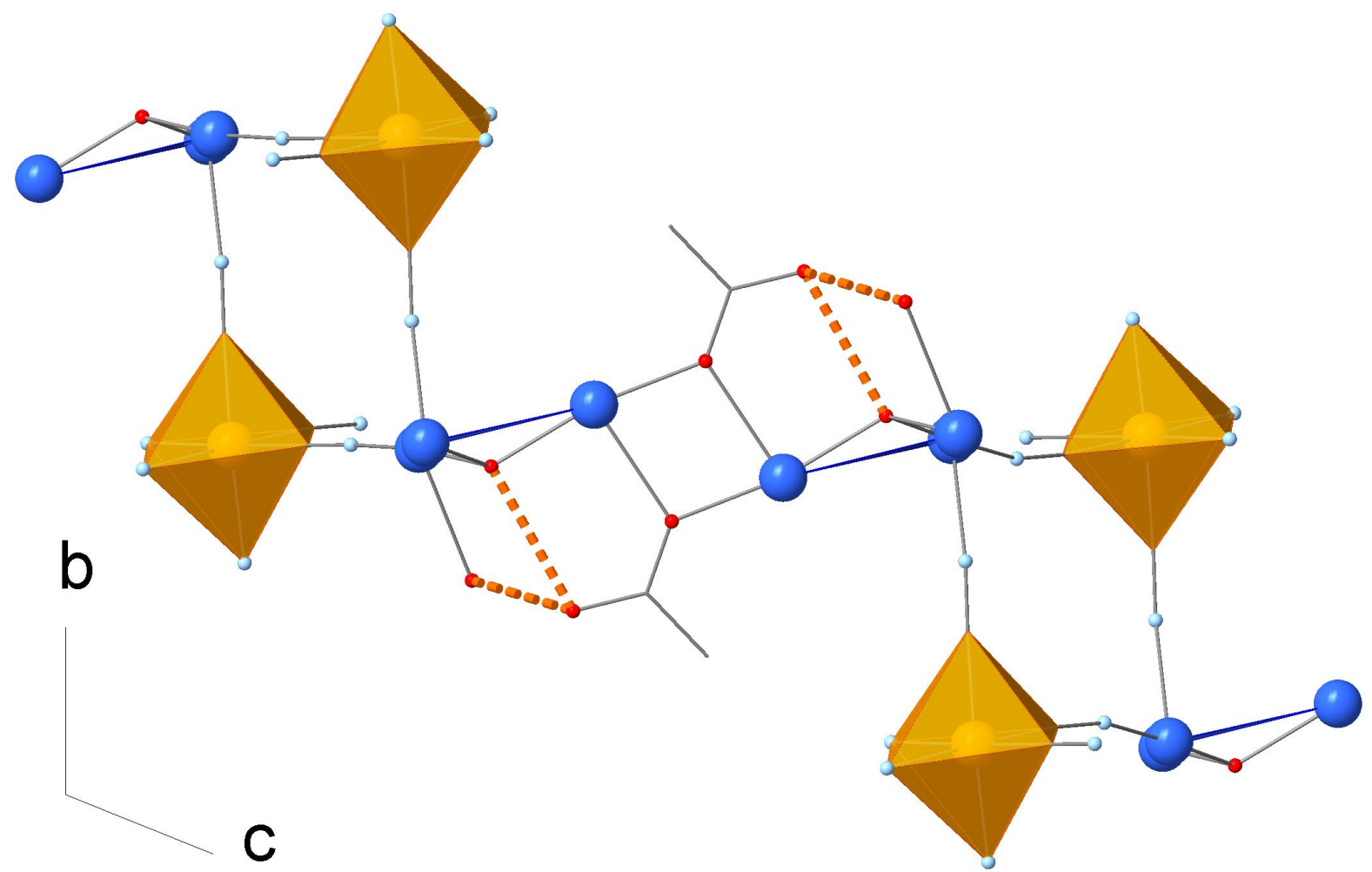

Figure S2: view of the hydrogen bonds (orange dotted lines) involving the $\left\{\mathrm{Cu}_{3}\right\}$ cluster. 


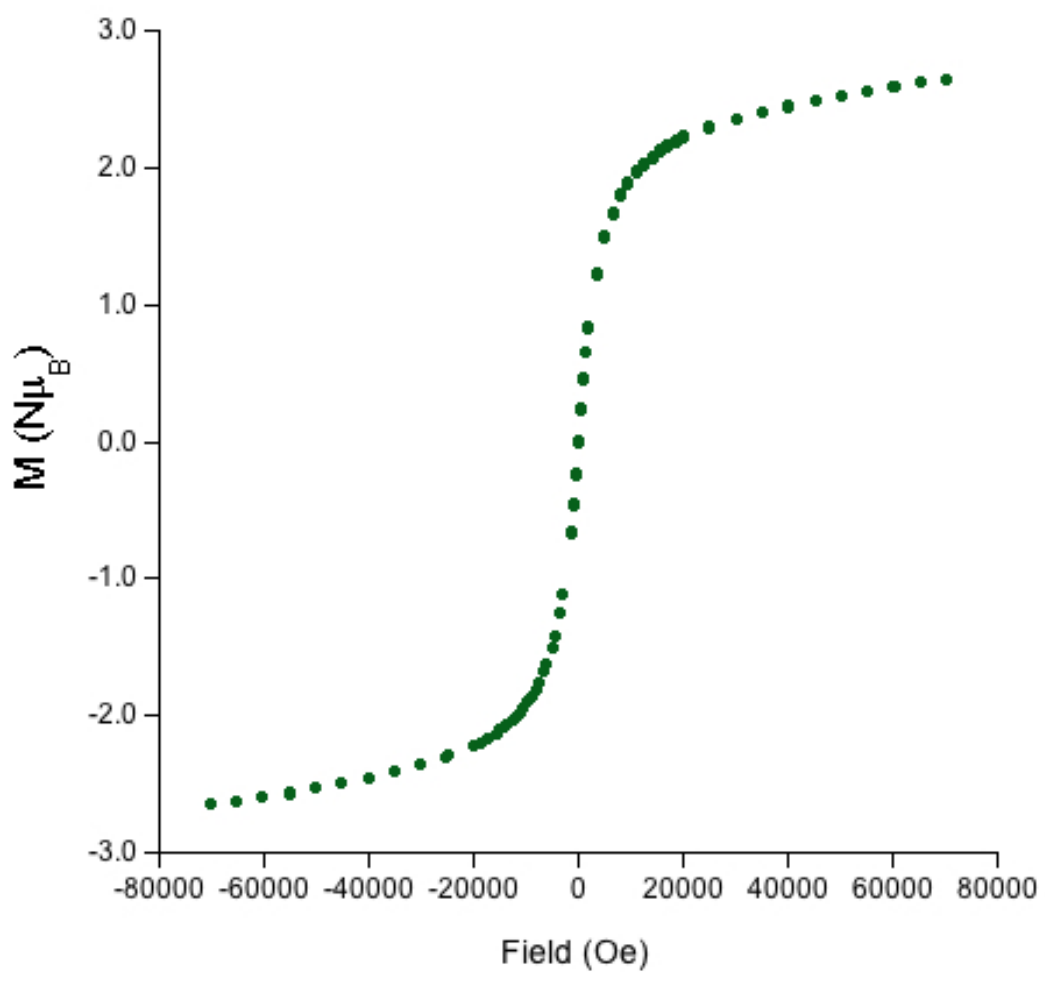

Figure S3: $\mathrm{M}$ vs. $\mathrm{H}$ plot for 1 measured between 1 and $7 \mathrm{~T}$ at $2 \mathrm{~K}$.

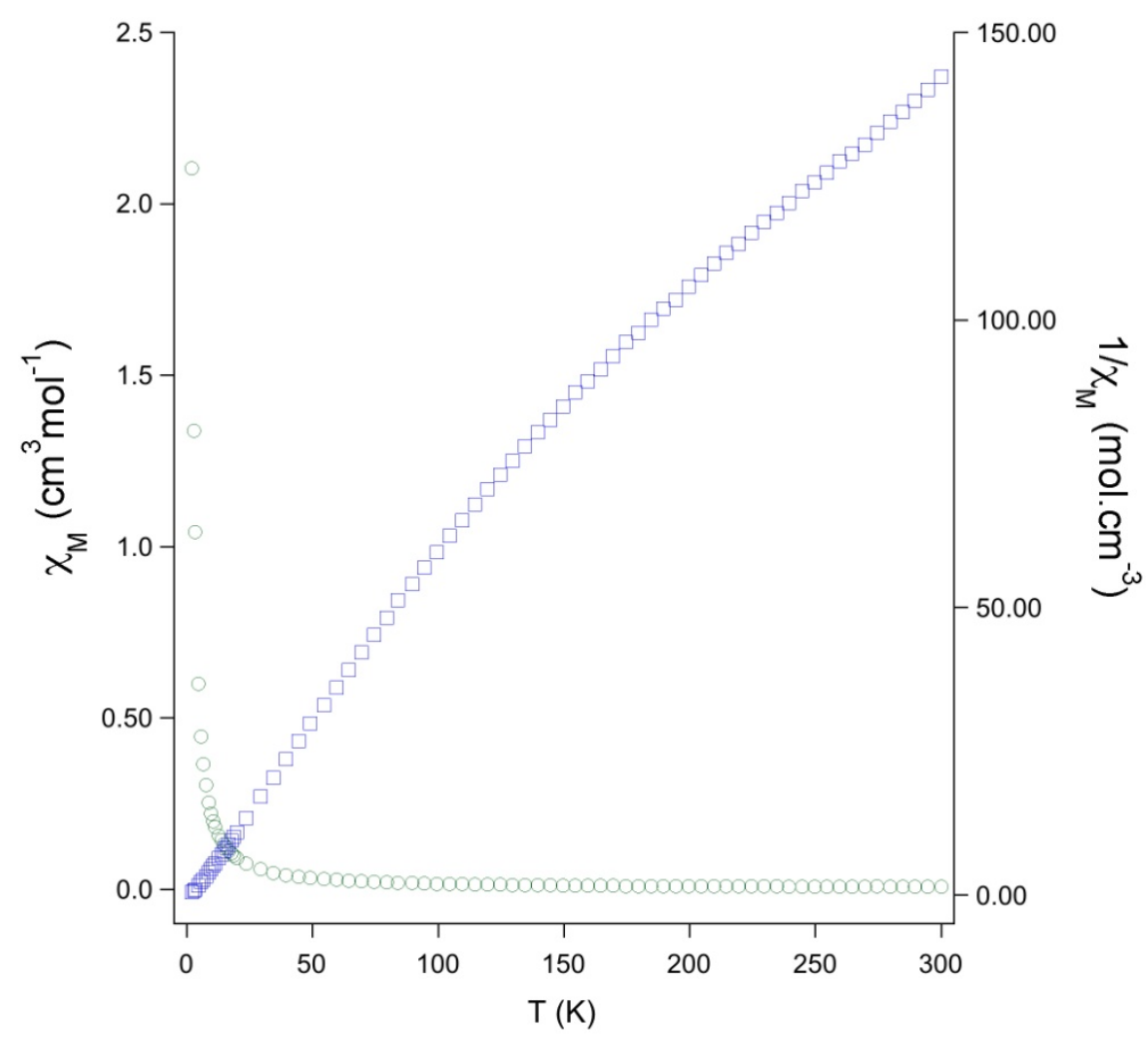

Figure S4: $\chi_{M} v s . T$ and $1 / \chi_{M} v s . T$ plots for 1 measured at $2.5 \mathrm{KOe}$ between 300 and $2 \mathrm{~K}$ 
(1) Lescouëzec, R.; Vaissermann, J.; Lloret, F.; Julve, M.; Verdaguer, M. Inorg. Chem. 2002, 41, 5943-5945.

(2) Casarin, M.; Corvaja, C.; Nicola, C. di; Falcomer, D.; Franco, L.; Monari, M.; Pandolfo, L.; Pettinari, C.; Piccinelli, F.; Tagliatesta, P. Inorg. Chem. 2004, 43, 5865-5876.

(3) CrysAlisPro CCD and CrisAlisPro RED; Oxford Diffraction Ltd., Yarnton, Oxfordshire, U.K.; 2009.

(4) Blessing, R. H. Crystallogr. Rev. 1987, 1, 3.

(5) Blessing, R. H. Acta Crystallogr., Sect. A 1995, 51, 33.

(6) Sheldrick, G. M. Acta Crystallogr., Sect. A 2008, 64, 112.

(7) Farrugia, L. J. J. Appl. Crystallogr. 1999, 32, 837. 